\title{
Harmonic Modeling and Experimental Validation of the Converters of DFIG-Based Wind Generation System
}

\author{
Yang-Wu Shen $\left(\mathbb{D},{ }^{1}\right.$ Ding Wang, ${ }^{1}$ Xiang-Tian Deng $\left(\mathbb{D},{ }^{2}\right.$ Qing $\mathrm{Li}^{3}{ }^{3}$ and Jian Zuo ${ }^{1}$ \\ ${ }^{1}$ State Grid Hunan Electric Power Corporation Limited Research Institute, Changsha, China \\ ${ }^{2}$ School of Automation, Wuhan University of Technology, Wuhan, China \\ ${ }^{3}$ China Electric Power Research Institute, Beijing, China \\ Correspondence should be addressed to Xiang-Tian Deng; dengxt@whut.edu.cn
}

Received 2 July 2019; Revised 29 August 2019; Accepted 14 September 2019; Published 3 November 2019

Guest Editor: Taesic Kim

Copyright (c) 2019 Yang-Wu Shen et al. This is an open access article distributed under the Creative Commons Attribution License, which permits unrestricted use, distribution, and reproduction in any medium, provided the original work is properly cited.

\begin{abstract}
The double-fed induction wind generator- (DFIG-) based wind generation system contains power electronic converters and filter capacitor and inductor, which will bring about high-frequency harmonics under the influence of controllers. Aiming at this problem, this paper studies the relation between the output current and the harmonic source at grid-side and rotor-side converters based on their control features in the DFIG system. Furthermore, the harmonic equivalent models of these two converters are built, and the influence of different factors on harmonic features is explored from four perspectives, i.e., modulation method, altering controller parameters, altering output power, and the unbalance of three-phase voltage. Finally, the effectiveness of the proposed model is verified through the 2 MW DFIG real-time hardware-in-the-loop test platform by StarSim software and real test data, respectively.
\end{abstract}

\section{Introduction}

New energy power generation technologies have become hot spots as the energy and environmental issues obtained prominent attention. Wind energy has been widely applied in power systems because of its clean, harmless, and abundant nature in natural resources. The double-fed wind power generation system has become the mainstream in wind power generation systems because of its small capacity in the field converter, low cost, and variable-speed constantfrequency operation features [1-6]. However, the double-fed wind power generation system contains a power electronic converter, in which the interactions among converters and passive components of the filter can lead to harmonic resonances, thus causing serious harmonic pollution and reducing the power quality [7-10].

With regard to the harmonic problem in the double-fed wind power generation system, relevant researches and analyses have been carried out [11-14]. In the literature [11], the source of stator harmonic current of the double-fed wind turbine is analyzed. It is pointed out that the harmonic modulation of the converter, the cogging harmonic of the motor itself, and the grid background harmonic affect the stator output harmonics of the double-fed wind turbine. In [12], the harmonic characteristics of the double-fed wind turbine converter are analyzed, and the effect of the converter harmonic on the system overall output harmonic is analyzed by establishing the equivalent circuit of the asynchronous motor. Based on the mathematically electromagnetic relationship of the asynchronous motor, literature [13] proposes a harmonic equivalent circuit of the double-fed asynchronous motor and studies the influence of harmonics generated by the wind turbine on the power grid. According to the characteristics of the asynchronous motor, literature [14] analyzes the interaction between the grid-side converter harmonic and the rotor-side converter harmonic in the double-fed wind power generation system.

From the above literature studies, the grid-side or rotorside converters in the double-fed wind power generation system are viewed as a simple harmonic voltage source when modeling and analyzing the converter output harmonic characteristics, while the influence of converter control 
factors on system harmonic output characteristics is not considered.

Literature studies $[15,16]$ point out that the harmonics generated by PWM (pulse-width modulation) are mainly distributed near the double switching frequency. Reference [17] studies the harmonic resonance characteristics of the photovoltaic power generation system by establishing the Norton equivalent model of the photovoltaic converter. Considering the control characteristics of different types of converters [18], Wang et al. establish the converter equivalent model of voltage source control and current source control, respectively.

However, there is little literature on the harmonic characteristics of the double-fed wind power generation system at present. The main contributions of this paper can be summarized as follows:

(1) Based on the existing harmonic model, the influence of component parameters and control parameters on the harmonic output of the RSC and GSC is studied, and the harmonic output characteristics of the RSC and GSC are summarized. Furthermore, a novel method for suppressing the output harmonic amplitude of the DFIG by adjusting PI control parameters is proposed, and the effectiveness of the proposed method has been verified by the simulation case.

(2) The harmonic model of the typical DFIG is established, and the parameters of the harmonic model of the DFIG are corrected by the measured data. With the correction of harmonic model parameters, the harmonic characteristics of the corrected harmonic model of the DFIG are consistent with the harmonic characteristics of the actual DFIG.

The rest of this paper is organized as follows: Section 2 presents the harmonic source analysis of the double-fed wind power generation system. Section 3 presents the characteristics analyses of the converter harmonic model. Case studies are presented in Section 4 to validate the proposed harmonic model of the DFIG. Conclusion is presented in Section 5.

\section{Harmonic Source Analysis of Double-Fed Wind Power Generation System}

The structure of the double-fed wind power generation system is shown in Figure 1. Two back-to-back PW-modulated converters are used for AC excitation through a DC link. Effective control of converters enables variable-speed constant-frequency operation and maximum wind energy tracking within a certain range $[10,19,20]$.

The harmonic sources of the double-fed wind power generation system mainly include the harmonics caused by the asynchronous motor itself and the harmonics caused by the converter modulation [14]. In addition, the output harmonic of the double-fed wind power system may exceed the standard when there are background harmonics in the grid and irrational converter control parameters. The cogging harmonics caused by the asynchronous motor itself due to the uneven air gap can be suppressed or eliminated by

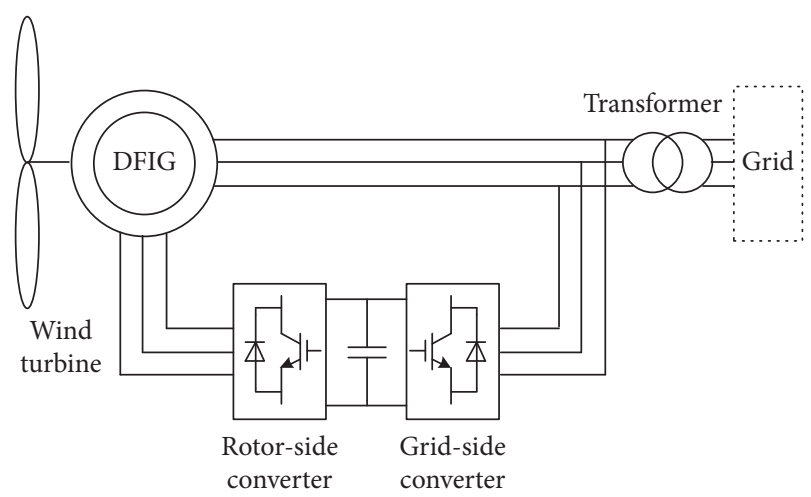

FIgUre 1: Double-fed wind power generation system.

rational motor structure designing. Thus, this paper mainly considers the PW modulation harmonics of the converter and the background harmonics of the power grid. The harmonic output characteristics of the double-fed wind power generation system are studied by establishing the harmonic equivalent model.

\section{Harmonic Modeling of Double-Fed Wind Power Converter}

Because of the fact that the dynamics of DC-side voltage is slower than the harmonic dynamics, the voltage across the capacitor between the grid-side converter and the rotor-side converter of the double-fed wind power system remains constant. Therefore, the two converters can be discussed separately in harmonic modeling. In this section, the harmonic equivalent models of the grid-side and rotor-side converters are established to study their harmonic output characteristics and influencing factors. Note that there are subsynchronous and low-frequency oscillations which lie below the fundamental frequency in wind power generation systems, and this paper mainly discusses the harmonics above the fundamental frequency [9].

The harmonic amplitude is proportional to the switching frequency, dead time, and DC-side voltage and inversely proportional to the harmonic order. The amplitude is negligible, so the voltage generated by the dead zone effect is mainly low, such as 3, 5, 7, and 9. For a converter with a high switching frequency, the dead time is long in one switching cycle, and the low-order harmonic generated by the dead zone is more obvious, while the large-capacity converter with a lower switching frequency is generated by the dead zone effect. In this paper, the switching delay of the converter is not taken into consideration for the harmonic model of converters.

3.1. Harmonic Modeling of Grid-Side Converter. For a threephase balancing system, the system can be equivalent to a single-phase system. The command signal of the inner current loop in the grid-side converter is given by the outer voltage loop. Consider the response of the voltage loop is much slower than the response of the current loop. Thus, by ignoring the voltage loop, the control block diagram of the 
grid-side converter is obtained and shown in Figure 2. The converter-side current feedback control which is more stable than the grid-side current feedback current control is adopted, as shown in Figure 2 [21].

In Figure 2, $K_{\mathrm{pwm}}$ is the linear gain of the pulse-width modulation (PWM) converter bridge, $i_{1 \text { ref }}$ is the reference of the current loop, $u_{g h}$ is the harmonic voltage generated by PWM, $G_{i g}$ is the transfer function of the current regulator which adopts the proportional resonance controller, and $u_{\text {PCC }}$ is the voltage at the grid-connected point. The harmonic model shown in Figure 2 considers two kinds of harmonic sources: (1) the harmonic voltage $u_{g h}$ generated by the PWM and (2) the grid background harmonic voltage $u_{\text {PCC }}$ at the grid-connected point.

In the steady-state operation, the current reference $i_{1 \text { ref }}$ remains constant [22]. Thus, according to the Mason formula, the complex frequency-domain expression among $i_{2}$, $u_{g h}$, and $u_{\text {PCC }}$ can be obtained as follows.

$$
i_{2}=N_{g}(s) u_{g h}-Y_{\text {eqg }}(s) u_{\mathrm{PCC}},
$$

where $s$ is the complex frequency-domain variable and $N_{g}(s)$ and $Y_{\text {eqg }}(s)$ are expressed as

$$
\left\{\begin{array}{l}
N_{g}(s)=\frac{Z_{C}}{Z_{1} Z_{2}+Z_{1} Z_{C}+Z_{2} Z_{C}+G_{i g} K_{\mathrm{pwm}}\left(Z_{2}+Z_{C}\right)}, \\
Y_{\text {eqg }}(s)=\frac{Z_{1}+Z_{C}+G_{i g} K_{\mathrm{pwm}}}{Z_{1} Z_{2}+Z_{1} Z_{C}+Z_{2} Z_{C}+G_{i g} K_{\mathrm{pwm}}\left(Z_{2}+Z_{C}\right)},
\end{array}\right.
$$

where $K_{\text {pwm }}$ is usually taken as $1 ; Z_{1}=s L_{1}+R_{1}, Z_{2}=s L_{2}+R_{2}$, and $Z_{C}=1 / s C$, in which $L_{1}, R_{1}, L_{2}$, and $R_{2}$ are the LCL filter inductance and equivalent resistance and $C$ is the filter capacitor; and $G_{i g}$ is expressed as

$$
G_{i g}=k_{p g}+\frac{s k_{i g}}{s^{2}+\omega_{g}^{2}},
$$

where $k_{p g}$ and $k_{i g}$ are the proportional and integral coefficients of the current controller and $\omega_{g}$ is the fundamental frequency.

According to Figure 1 and (1), the Norton equivalent circuit of the grid-side converter can be obtained, which is shown in Figure 3. In Figure 3, $N_{g}(s) u_{g h}$ is the PWmodulated harmonic and $u_{\mathrm{PCC}}$ is the grid background harmonic.

3.2. Harmonic Modeling of Rotor-Side Converter. The rotorside converter adopts the motor stator flux-oriented feedforward decoupling control. The outer control loop is the speed control or active power control, and the output of the outer loop controller is the reference of the inner current loop. Similarly, the response of the inner loop is much faster than that of the outer loop. Therefore, the outer control loop is neglected, and the balanced three-phase system is equivalent to a single-phase system. The current control block diagram of the rotor-side converter is shown in Figure 4.

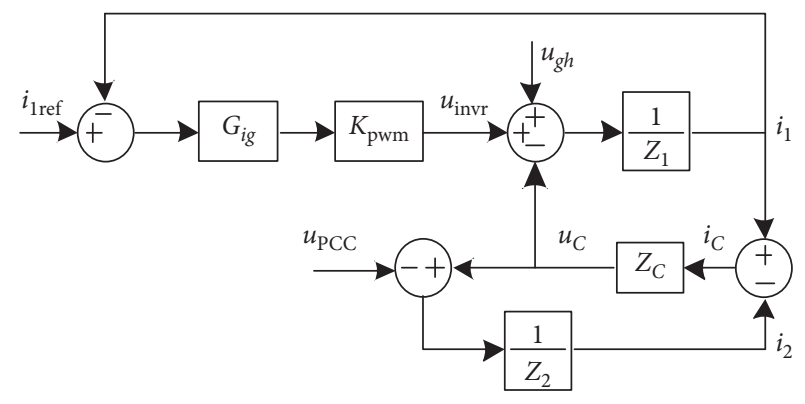

FIGURE 2: Current control block diagram of the grid-side converter.

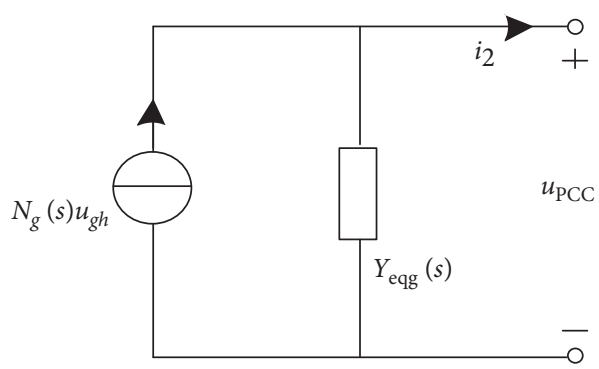

Figure 3: Norton equivalent circuit of the grid-side converter.

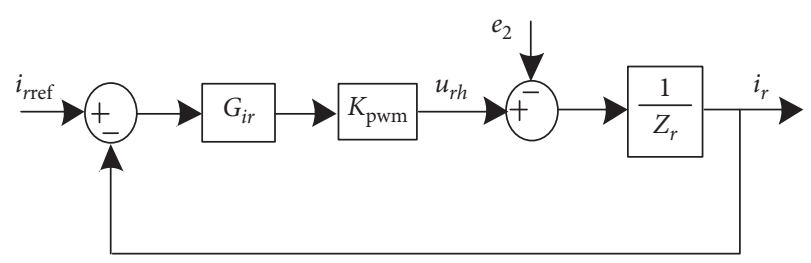

FIGURE 4: Current control block diagram of the rotor-side converter.

In Figure $4, i_{r \text { ref }}$ is the current reference, $u_{r h}$ is the harmonic voltage generated by PWM, and $G_{i r}$ is the transfer function of the current controller and the proportional resonance controller is used; $e_{2}$ is the rotor-side phase electromotive force of the asynchronous machine. In Figure 4 , the output current is

$$
i_{r}=N_{r}\left(s^{\prime}\right) u_{r h}-Y_{\text {eqr }}\left(s^{\prime}\right) e_{2}
$$

where $s^{\prime}$ is the rotor-side complex frequency-domain variable. Note that $s^{\prime}=s_{\text {slip }}$, where $s_{\text {slip }}$ is the slip. The detailed expressions of $s_{\text {slip }}, N_{r}\left(s^{\prime}\right)$, and $Y_{\text {eqr }}\left(s^{\prime}\right)$ are shown as follows:

$$
\left\{\begin{array}{l}
s_{\text {slip }}=\frac{s-j \omega_{m}}{s}, \\
N_{r}\left(s^{\prime}\right)=\frac{1}{Z_{r}+G_{i r} K_{\mathrm{pwm}}}, \\
Y_{\mathrm{eqr}}\left(s^{\prime}\right)=\frac{1}{Z_{r}+G_{i r} K_{\mathrm{pwm}}},
\end{array}\right.
$$

where $\omega_{m}$ is the rotor speed of the asynchronous motor; $Z_{r}=s^{\prime} L_{r}+R_{r}$, in which $L_{r}$ and $R_{r}$ are the rotor leakage inductance and resistance; and $G_{i r}$ is expressed as 


$$
G_{i r}=k_{p r}+\frac{s^{\prime} k_{i r}}{s^{\prime 2}+\left(\omega_{g}-\omega_{m}\right)^{2}},
$$

where $k_{p r}$ and $k_{i r}$ are the proportional and integral coefficients of the current controller, respectively.

According to Figure 4 and (4) and combining with the asynchronous motor equivalent circuit $[11,12]$, the Norton equivalent model of the rotor-side converter can be obtained, which is shown in Figure 5(a). Note that the rotor-side variables are converted to the stator side by the generator conversion. With the circuit conversion, Figure 5(a) can be equivalent to Figure 5(b). From Figure 5(b), we have

$$
i_{s}=N_{s}(s) u_{r h}-Y_{\text {eqs }}(s) u_{\mathrm{PCC}}
$$

where $i_{s}$ is the stator-side output current of the asynchronous motor and $N_{s}(s)$ and $Y_{\text {eqs }}(s)$ are expressed as

$$
\left\{\begin{array}{c}
N_{s}(s)=\frac{Z_{m} N_{r}\left(s^{\prime}\right)}{Z_{m}+Z_{s}+s_{\text {slip }} Y_{\text {eqr }}\left(s^{\prime}\right) Z_{m} Z_{s}}, \\
Y_{\text {eqs }}(s)=\frac{1+s_{\text {slip }} Y_{\text {eqr }}\left(s^{\prime}\right) Z_{m}}{Z_{m}+Z_{s}+s_{\text {slip }} Y_{\text {eqr }}\left(s^{\prime}\right) Z_{m} Z_{s}},
\end{array}\right.
$$

where $Z_{m}=s L_{m}$ and $Z_{s}=s L_{s}+R_{s}$, in which $L_{m}$ is the excitation inductance of the asynchronous motor and $L_{s}$ and $R_{s}$ are the stator leakage inductance and resistance.

\section{Characteristics Analyses of Converter Harmonic Model}

Based on the harmonic models of grid-side and rotorside converters established in Section 3, the effects of component parameters and control parameters on harmonic characteristics are studied. The detailed parameters of the DFIG used in the simulation are shown in Table 1.

4.1. Characteristic Analysis of Harmonic Model of Grid-Side Converter. According to the Norton equivalent model shown in Figure 3 and (1) and (2), the Bode diagram of $N_{g}(s)$ and $Y_{\text {eqg }}(s)$ is shown in Figure 6. It can be seen from the figure that there are resonance peaks (magnitude greater than $0 \mathrm{~dB}$ ) at a frequency of about $1450 \mathrm{~Hz}$ in $N_{g}(s)$ and $Y_{\text {eqg }}(s)$. It indicates that the converter output current will undergo harmonic amplification when the frequency of $u_{g h}$ and $u_{\text {PCC }}$ is close to the resonant frequency, thus affecting the power quality. Besides, it should be noted that the magnitude-frequency curves of $N_{g}(s)$ and $Y_{\text {eqg }}(s)$ are obviously declining when the frequency is higher than $2000 \mathrm{~Hz}$, indicating that the converter has a strong suppression to high-frequency harmonics.

Ignoring the equivalent resistance of the filter inductor as it is usually small, and taking $K_{\text {pwm }}=1$, the denominator of $N_{g}(s)$ and $Y_{\text {eqg }}(s)$ shown in (2) can be expanded to

$$
\begin{aligned}
\operatorname{den}_{g}= & \frac{1}{s C}\left[s^{3} C L_{1} L_{2}+s\left(L_{1}+L_{2}\right)+s^{2} k_{p g} C L_{2}+k_{p g}\right. \\
& \left.+\frac{s^{2} k_{i g} C L_{2}}{s^{2}+\omega_{g}^{2}}+\frac{s k_{i g}}{s^{2}+\omega_{g}^{2}}\right] .
\end{aligned}
$$

It can be seen from (9) that the cubic term and the primary term of $s$ in the brackets form a pair of resonant poles whose resonant frequency is

$$
\omega_{r g}= \pm \sqrt{\frac{L_{1}+L_{2}}{C L_{1} L_{2}}}
$$

The resonant frequency $\omega_{r g}$ calculated by $(10)$ is coincident with the resonant frequency of the LCL filter. Therefore, it can be inferred that the resonant peak in Figure 6 is determined by the filter inductance. This means that choosing the right filter parameters can suppress as many harmonics as possible in the high frequency. Since the PWM harmonics are mainly concentrated near the double switching frequency $[15,16]$, the harmonic frequency is higher and can be suppressed. The range of grid background harmonic frequency is wide, and there are many lower harmonics such as the $5^{\text {th }}, 7^{\text {th }}$, and $11^{\text {th }}$. Therefore, it is necessary to further study the harmonic output characteristics of the converter affected by the grid background harmonics.

In the vicinity of the resonant frequency $\omega_{r g}$, an approximate expression is obtained as $s_{2} \gg \omega g_{2}$ and the capacitance of the filter capacitor is small.

$$
\operatorname{den}_{g} \approx s^{2} L_{1} L_{2}+\frac{L_{1}+L_{2}}{C}+s k_{p g} L_{2} .
$$

It is not difficult to see from (11) that the product of $k_{p g}$ and $L_{2}$ provides damping for the resonance. The larger the product, the stronger the damping effect.

Since the current control parameter $k_{p g}$ is relatively easier to change than $L_{2}$ in practice, only the influence of $k_{p g}$ is studied in Figure 7.

It can be seen from Figure 7 that when the parameter of the current loop controller $k_{p g}$ is relatively small, the magnitude-frequency curve of $Y_{\text {eqg }}(s)$ has a resonance peak. As $k_{p g}$ increases, the resonance peak gradually decreases to disappear. In addition, Figure 7 also shows that the controller parameter $k_{p i}$ has less effect on the magnitude-frequency curve of $Y_{\text {eqg }}(s)$ since the integral term of $G_{i g}$ is almost zero at high frequencies.

In summary, the existence of LCL filter resonance may cause harmonic amplification in the output of the grid-side converter of the wind power generation system, and the resonance can be suppressed by adjusting the parameter of the current controller $k_{p g}$. It should be noted that $k_{p g}$ also affects the dynamic response and stability of the converter control system, and this is beyond the scope of this paper. Therefore, the parameter $k_{p g}$ should be increased as much as possible to suppress the harmonic output of the converter under the premise of meeting the dynamic performance and stability requirements of the system. 


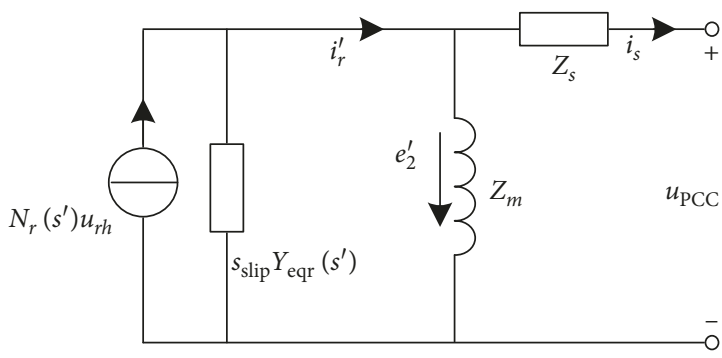

(a)

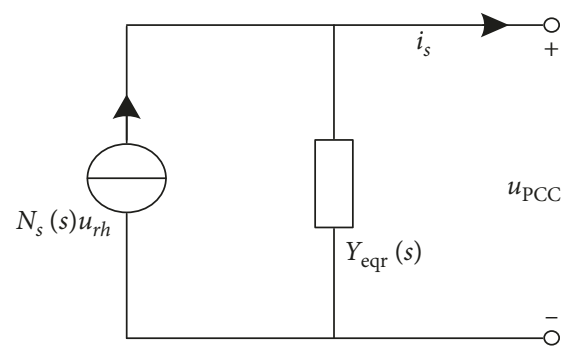

(b)

FIGURE 5: Norton equivalent circuit of the rotor-side converter: (a) detailed circuit of the rotor-side converter and asynchronous machine; (b) equivalent model.

TABLE 1: Detailed parameters of the DFIG simulation platform.

\begin{tabular}{lc}
\hline Parameters & Values \\
\hline LCL filter $\left(L_{1}\right)$ & $2 \mathrm{mH}$ \\
LCL filter $\left(L_{2}\right)$ & $1 \mathrm{mH}$ \\
LCL filter $(C)$ & $18 \mu \mathrm{F}$ \\
Asynchronous motor $\left(L_{r}\right)$ & $0.404 \mathrm{mH}$ \\
Asynchronous motor $\left(R_{r}\right)$ & $0.0079 \Omega$ \\
Asynchronous motor $\left(L_{s}\right)$ & $0.08 \mathrm{mH}$ \\
Asynchronous motor $\left(R_{s}\right)$ & $0.0025 \Omega$ \\
Asynchronous motor $\left(L_{m}\right)$ & $4.4 \mathrm{mH}$ \\
$s_{\text {slip }}$ & -0.2 \\
\hline
\end{tabular}

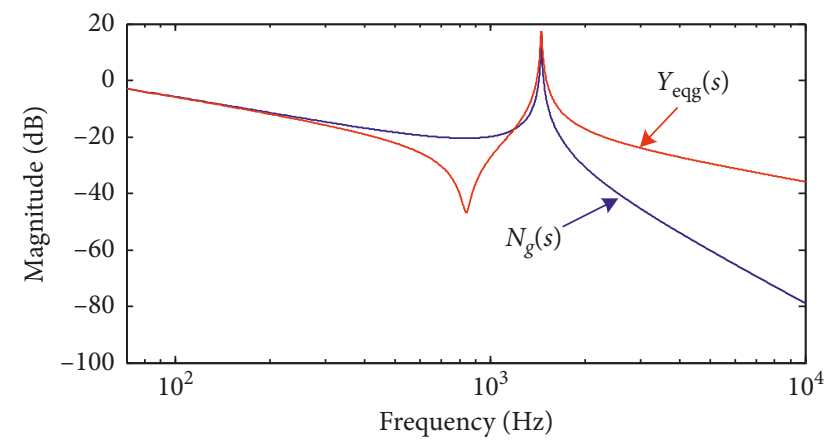

FIgURE 6: Magnitude-frequency curves of $N_{g}(s)$ and $Y_{\text {eqg }}(s)$.

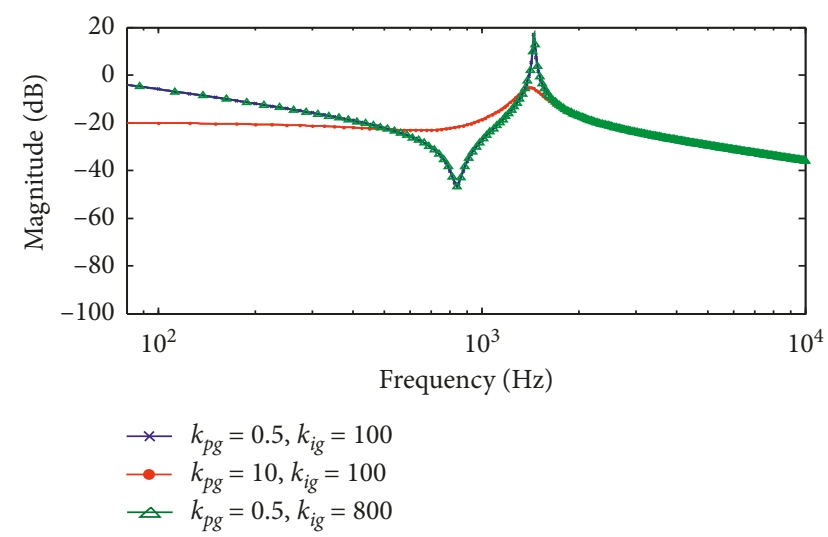

Figure 7: Magnitude-frequency curves of $Y_{\text {eqg }}(s)$ with different $k_{p g}$.

4.2. Characteristic Analysis of Harmonic Model of Rotor-Side Converter. According to (4)-(8) and Figure 5, the magnitude-frequency curves of $N_{s}(s)$ and $Y_{\text {eqs }}(s)$ are obtained and

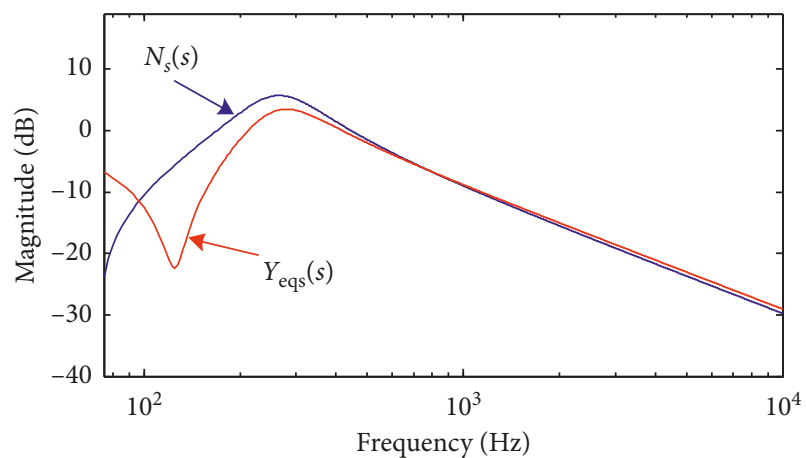

FIgURE 8: Magnitude-frequency curves of $N_{s}(s)$ and $Y_{\text {eqs }}(s)$.

shown in Figure 8. It can be seen from the curves in Figure 8 that, at higher frequencies, the rotor-side converter has an effect of suppressing the higher-frequency PWM harmonics and the grid background harmonics. Since there is no capacitor in the rotor-side converter and asynchronous motor, the magnitude-frequency curves of $N_{s}(s)$ and $Y_{\text {eqs }}(s)$ do not show obvious resonance peaks. However, it should also be noted that, at lower frequencies (about $300 \mathrm{~Hz}$ in Figure 8), there are peak slopes (magnitude exceeds $0 \mathrm{~dB}$ ). Thus, further characteristic study of $Y_{\text {eqs }}(s)$ is needed for the lower secondary grid background harmonics.

As to the rotor-side converter, the denominator of $N_{r}\left(s^{\prime}\right)$ and $Y_{\text {ekr }}\left(s^{\prime}\right)$ in (5) can be expanded $\left(R_{r}\right.$ is ignored and $K_{\text {pwm }}=1$ is considered for the same reason) to

$$
\begin{aligned}
\operatorname{den}_{r} & =s^{\prime} L_{r}+k_{p r}+\frac{s^{\prime} k_{i r}}{s^{\prime 2}+\left(\omega_{g}-\omega_{m}\right)^{2}} \\
& =\left(s-j \omega_{m}\right) L_{r}+k_{p r}+\frac{\left(s-j \omega_{m}\right) k_{i r}}{\left(s-j \omega_{m}\right)^{2}+\left(\omega_{g}-\omega_{m}\right)^{2}} .
\end{aligned}
$$

It can be seen from (12) that when the frequency is 3 times higher than the fundamental frequency of the rotor, that is, $s-j \omega_{m}>3\left(\omega_{g}-\omega_{m}\right)$ (it is considered that the smaller term can be ignored when the difference between two terms is more than 10 times in engineering application), the denominator $\operatorname{den}_{r}$ can be approximated to

$$
\operatorname{den}_{r} \approx\left(s-j \omega_{m}\right) L_{r}+k_{p r}+\frac{k_{i r}}{s-j \omega_{m}} .
$$


With (13), it can be found that the first and third terms form a pair of resonant poles whose resonant frequency is

$$
\omega_{r r}=\omega_{m} \pm \sqrt{\frac{k_{i r}}{L_{r}}} .
$$

Although there is no resonance in the rotor-side converter caused by the capacitor and inductor of the LCL filter, (14) shows that there will be resonance caused by the interaction between the controller integral term and the rotor leakage inductance. Besides, it can be seen from (8) that this resonance will be finally reflected to the stator side by $N_{s}(s)$ and $Y_{\text {eqs }}(s)$.

From (13) and (14), the resonant frequency is related to the rotor speed $\omega_{m}$, the rotor leakage inductance $L_{r}$, and the controller parameter $k_{i r}$. The rotor leakage inductance $L_{r}$ is related to the motor parameters and is fixed after the motor is manufactured. The rotor speed varies according to the actual wind speed, and the range of variation is limited. Only the controller parameter $k_{i r}$ is easy to change. Similar to the grid-side converter, the controller parameter $k_{p r}$ has an effect of damping.

Figure 9 shows the magnitude-frequency curves of $Y_{\text {eqs }}(s)$ with different $k_{i r}, k_{p r}$, and $\omega_{m}$. It can be seen from Figure 9 that, on increasing $k_{i r}$, the peak slope of $Y_{\text {eqs }}(s)$ shifts to a lower frequency and the magnitude decreases. On the contrary, the magnitude-frequency curve of $Y_{\text {eqs }}(s)$ declines to a large extent as $k_{p r}$ is increased. The slip $s_{\text {slip }}$ changes from -0.2 (corresponding to $\omega_{m}=1.2 \omega_{g}$ ) to -0.1 (corresponding to $\omega_{m}=1.1 \omega_{g}$ ), and the peak slope of $Y_{\text {eqs }}(s)$ shifts to a lower frequency. Considering that the actual range of slip variation is small, the parameters $k_{p r}$ and $k_{i r}$ are the main factors affecting the harmonic output characteristics of the rotor-side converter.

\subsection{Harmonic Model of Double-Fed Wind Power Generation} System considering Grid Impedance. According to the equivalent harmonic models of grid-side and rotor-side converters shown in Figures 3 and 5, the overall equivalent harmonic model of the double-fed wind system is shown in Figure 10. In Figure $10, Z_{g}$ is the grid equivalent impedance and $u_{g}$ is the grid voltage. According to Figure 10, the current $i_{g}$ can be obtained as

$$
i_{g}=N_{g g}(s) u_{g h}+N_{s g}(s) u_{r h}-Y_{g g}(s) u_{g},
$$

where $N_{g g}(s), N_{s g}(s)$, and $Y_{g g}(s)$ are shown as follows:

$$
\left\{\begin{array}{l}
N_{g g}(s)=\frac{N_{g}(s)}{1+Z_{g}\left(Y_{\mathrm{eqg}}(s)+Y_{\mathrm{eqs}}(s)\right)} \\
N_{s g}(s)=\frac{N_{s}(s)}{1+Z_{g}\left(Y_{\mathrm{eqg}}(s)+Y_{\mathrm{eqs}}(s)\right)} \\
Y_{g g}(s)=\frac{Y_{\mathrm{eqg}}(s)+Y_{\mathrm{eqs}}(s)}{1+Z_{g}\left(Y_{\mathrm{eqg}}(s)+Y_{\mathrm{eqs}}(s)\right)}
\end{array}\right.
$$

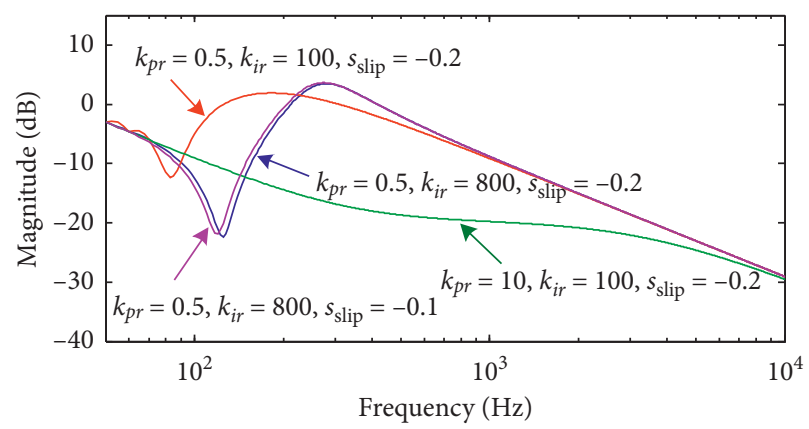

FIGURE 9: Magnitude-frequency curves of $Y_{\text {eqs }}(s)$.

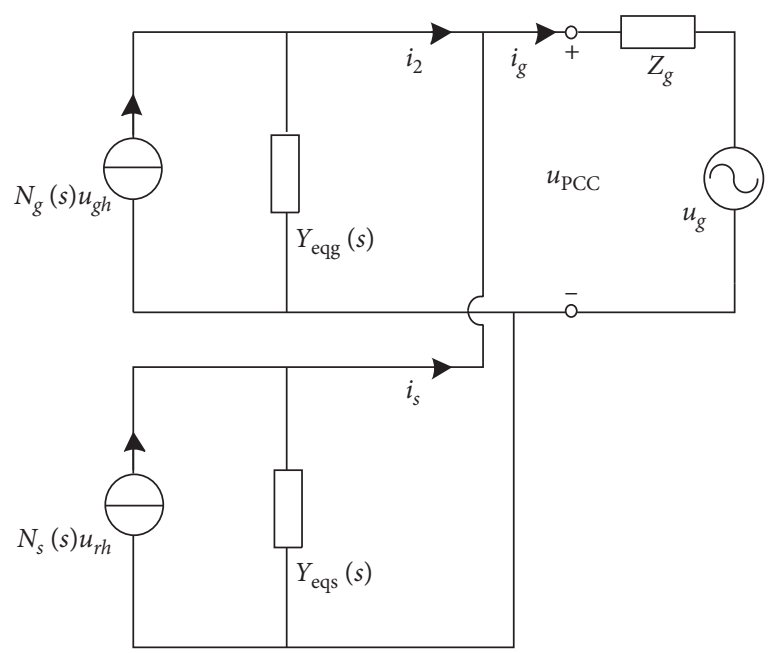

Figure 10: Norton equivalent circuit of the double-fed wind generator.

Considering the influence of grid background harmonics, the magnitude-frequency curve of $Y_{g g}(s)$ according to (15) and (16) is shown in Figure 11. It can be seen from Figure 11 that when there exists significant resonance in both $Y_{\text {eqg }}(s)$ and $Y_{\text {eqg }}(s)$, there appears similar resonant frequency in $Y_{g g}(s)$. The resonant peak of $Y_{g g}(s)$ is suppressed as the parameters $k_{p g}, k_{p r}$, and $k_{i r}$ are appropriately increased, which shows similar features to $Y_{\text {eqg }}(s)$ and $Y_{\text {eqg }}(s)$ in Figures 7 and 9. Therefore, in the presence of the grid impedance, the grid background harmonics still can be suppressed by appropriately adjusting the controller parameters.

\section{Case Study}

5.1. Simulation Verification. In order to verify the above characteristics analyses, a real-time hardware-in-the-loop (HIL) system from ModelingTech is built, as shown in Figure 12. Each electromagnetic transient model of the DFIG and control algorithm is constructed by StarSim software and implemented on NI FPGA board 7868R (real-time simulator). The control algorithm is implemented on the PXIe-8821 controller (rapid control prototype (RCP)). 


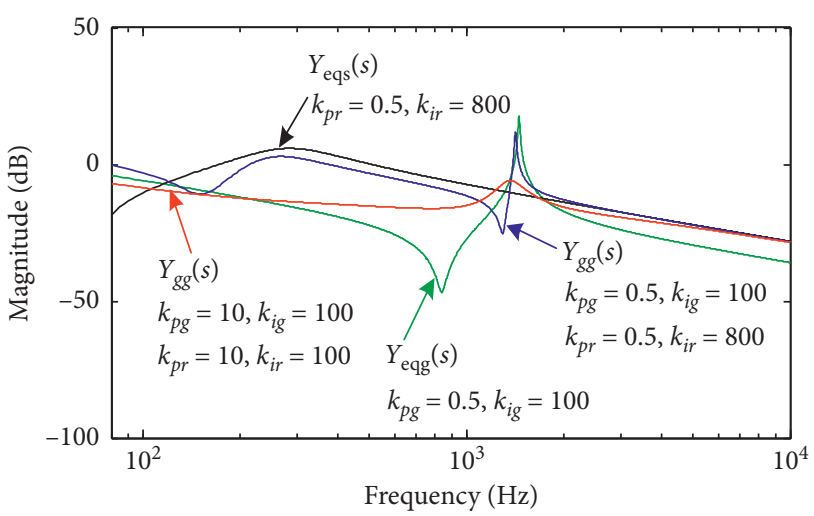

Figure 11: Magnitude-frequency curves of $Y_{\text {eqs }}(s), Y_{\text {eqg }}(s)$, and $Y_{g g}(s)$.

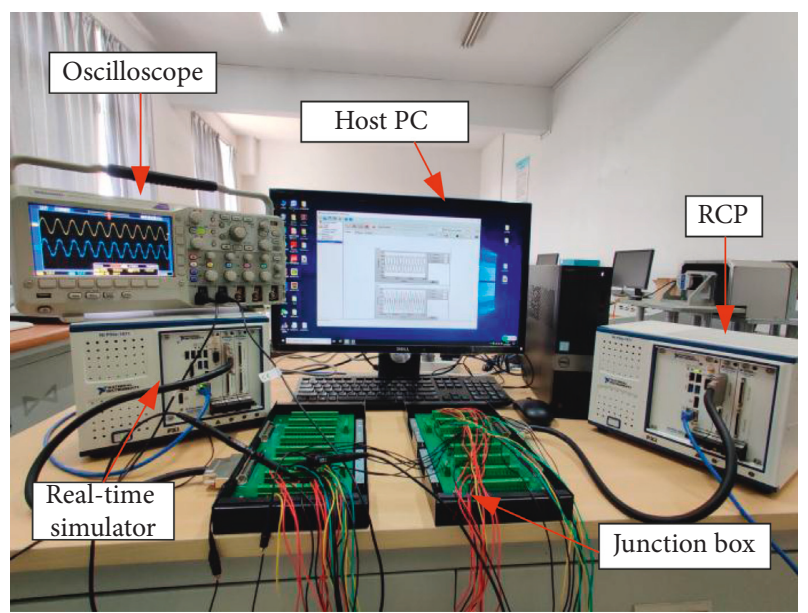

FIgURE 12: HIL simulation platform.

The LCL filter parameters of the grid-side converter are $L_{1}=2 \mathrm{mH}, L_{2}=1 \mathrm{mH}$, and $C=18 \mu \mathrm{F}$. The asynchronous motor parameters are $L_{r}=0.404 \mathrm{mH}, \quad R_{r}=0.0079 \Omega$, $L s=0.08 \mathrm{mH}, R_{s}=0.0025 \Omega, L_{m}=4.4 \mathrm{mH}$, and $s_{\text {slip }}=-0.2$. The grid equivalent inductance is $L_{1}=0.1 \mathrm{mH}$. The $5^{\text {th }}, 7^{\text {th }}$, $11^{\text {th }}, 13^{\text {th }}, 17^{\text {th }}, 19^{\text {th }}, 23^{\text {rd }}, 25^{\text {th }}, 29^{\text {th }}, 31^{\text {st }}, 35^{\text {th }}$, and $37^{\text {th }}$ harmonic sources with a magnitude of 0.02 pu are in series on the grid.

Figure 13 shows the grid-side converter output current $i_{g a}$, the asynchronous motor stator-side current $i_{s a}$, and the grid current $i_{a}$ for different control parameter cases. Figure 13 shows the magnitude of harmonic current measured under different cases. The parameters in different cases are set as follows: (1) case 1: $k_{p g}=0.5, k_{i g}=100, k_{p r}=0.5$, and $k_{i r}=800 ;(2)$ case $2: k_{p g}=10, k_{i g}=100, k_{p r}=0.5$, and $k_{i r}=800$; (3) case 3: $k_{p g}=0.5, k_{i g}=100, k_{p r}=10$, and $k_{i r}=100$; and (4) case $4: k_{p g}=10, k_{i g}=100, k_{p r}=10$, and $k_{i r}=100$.

Figures 13(a) and 14 show that there are both highfrequency harmonic amplification (about $29^{\text {th }}$ resonance frequency amplification due to LCL filter resonance) and low-frequency harmonic amplification (about $5^{\text {th }}$ and $7^{\text {th }}$ harmonic amplification caused by improper control parameters of the rotor-side converter) due to the presence of harmonic voltages in the grid. Figures 13(b), 13(d), and 14 show that, by appropriately increasing $k_{p g}$, it is possible to suppress the high-frequency harmonic (nearby $29^{\text {th }}$ harmonic current) caused by the resonance of the LCL filter.

Figures 13(c), 13(d), and 14 show that a proper increase in $k_{p r}$ and a decrease in $k_{i r}$ can suppress the low-frequency harmonic (near $5^{\text {th }}$ and $7^{\text {th }}$ harmonic current) caused by inappropriate rotor-side converter control parameters. The simulation results are consistent with the theoretical analyses.

5.2. Experiment Test. To further verify the theory, a test platform containing the actual wind power converter is built in the laboratory, as shown in Figure 15. In the test platform, the AC servo motor is used to emulate the wind turbine and an actual wind power converter is adopted. The rated voltages of the DFIG and the grid are $690 \mathrm{~V}$ and $380 \mathrm{~V}$, respectively, which are connected by a transformer.

The rated power of the converter is $2.0 \mathrm{MW}$. LC filters are utilized for the grid-side converter, with the inductance of filtering being $0.43 \mathrm{mH}$. Three-phase capacitors are connected in a triangle shape, and the capacitance is $120 \mu \mathrm{F}$. LC filters and the grid-side line resistances together with the transformer equivalent impedance are combined into an LCL filter. L filters are used on the rotor side, with the inductance being $0.15 \mathrm{mH}$. The switch frequency of the converter on the grid side is $3000 \mathrm{~Hz}$ and that on the rotor side is $2000 \mathrm{~Hz}$, and the modulation method is SVPWM. The $\mathrm{DC}$-side voltage is $1050 \mathrm{~V}$, and the AC-side grid frequency is $50 \mathrm{~Hz}$. The detailed parameters of the test platform are shown in Table 2.

The acquisition device is installed at PCC to obtain samples of voltage and current signals synchronously, with the sampling rate being $6000 \mathrm{~Hz}$. In this part, the accuracy of the proposed harmonic modeling of the DFIG is verified from four perspectives, i.e., modulation method, altering controller parameters, altering output power, and the unbalance of three-phase voltage.

5.2.1. Modulation Method. Figure 16 shows the waveforms of the voltage and current at PCC, as well as their harmonic spectrums. The switch frequency of the grid-side converter and rotor-side converter is $3000 \mathrm{~Hz}$ and $2000 \mathrm{~Hz}$, respectively, and there are obvious harmonics with high frequency close to switch frequency. The high-frequency harmonic components of the voltage and current are distributed at 1920,1980,2020, and $2080 \mathrm{~Hz}$ for the grid-side converter and 2800 and $2900 \mathrm{~Hz}$ for the rotor-side converter.

5.2.2. Altering Control Parameters. In order to study the influence of different controller parameters on the current harmonic components at PCC, different PI controller's parameters of the inner current loop are set for the DFIG's grid-side converter. Specifically, at first, $k_{p}$ is set to be 0.23 and 0.71 , respectively, when $k_{i}$ remains as 30 . Secondly, $k_{p}$ is set to be 21 and 45 , respectively, when $k i$ remains as 0.45 . Figure 17 shows the output current harmonic spectrums of the DFIG converter under different PI control parameters. 


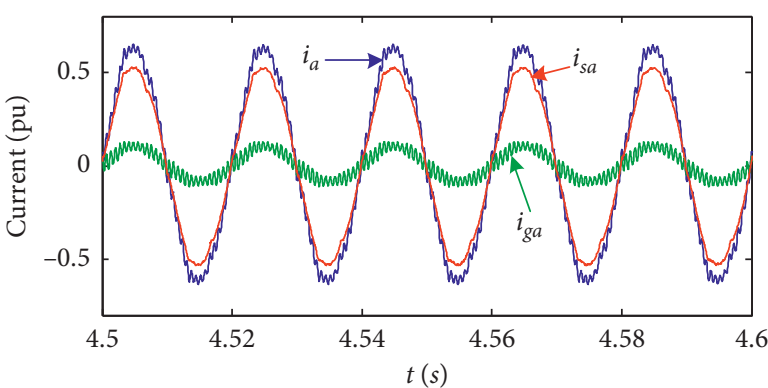

(a)

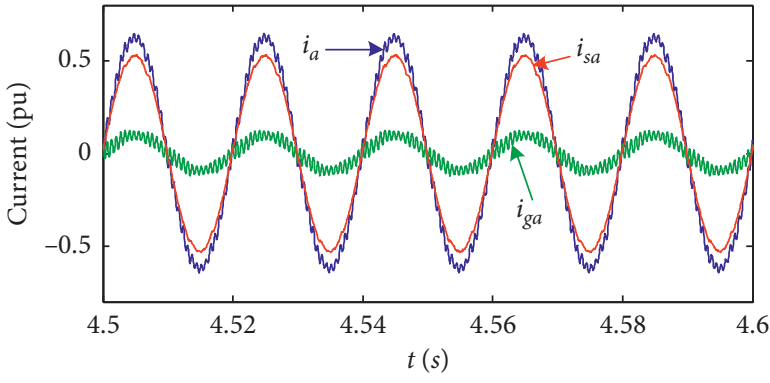

(c)

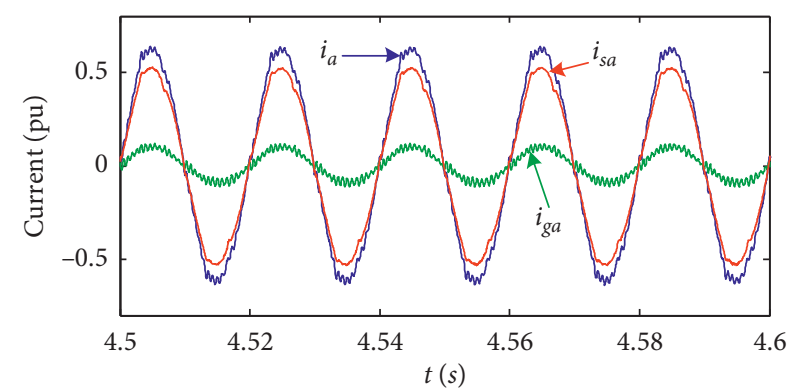

(b)

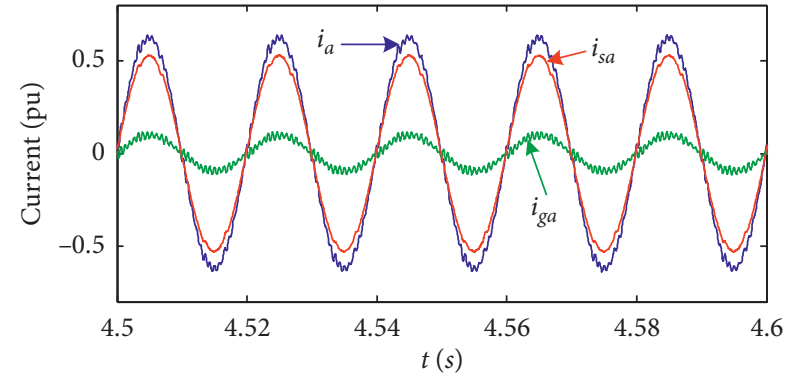

(d)

FIgURE 13: Currents $i_{g a}, i_{s a}$, and $i_{a}$ : (a) case 1; (b) case 2; (c) case 3; (d) case 4 .

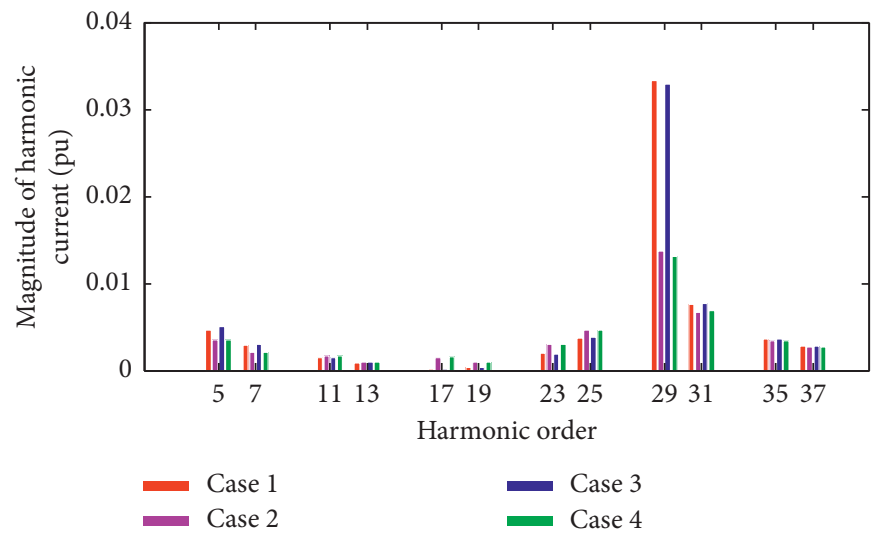

(a)

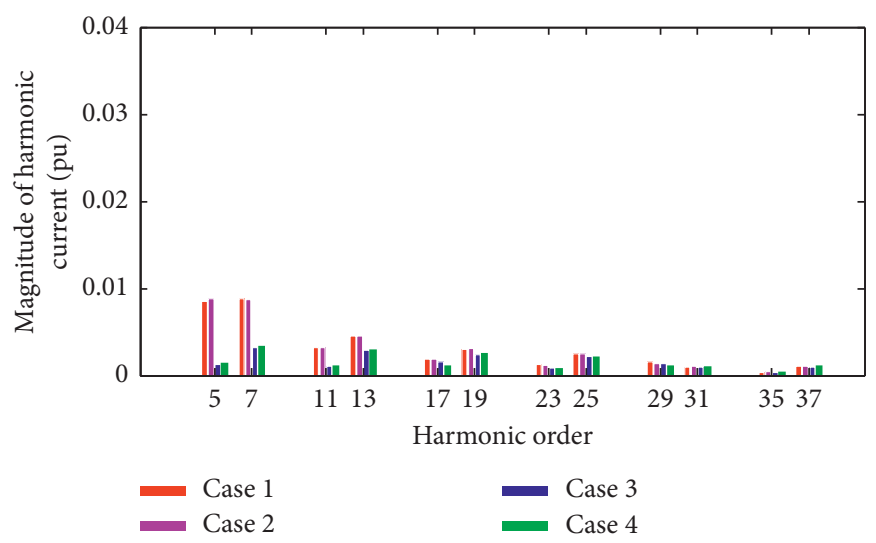

(b) 


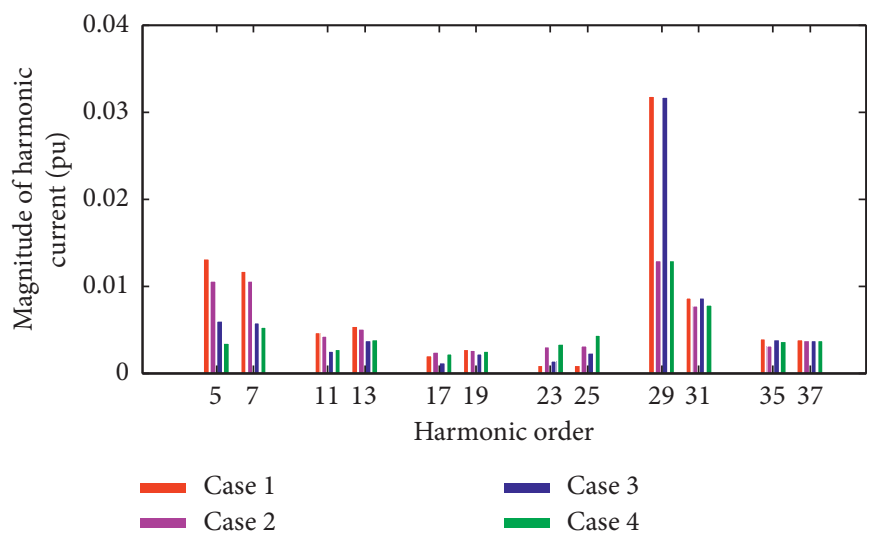

(c)

FIgURE 14: Harmonic current graphs of (a) $i_{g a}$, (b) $i_{s a}$, and (c) $i_{a}$.

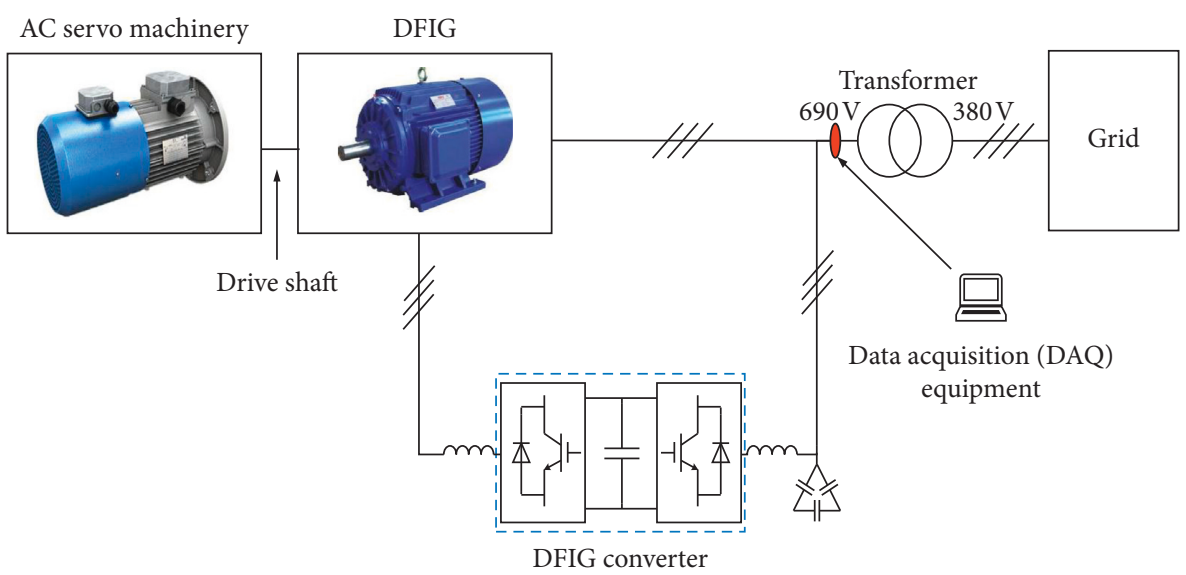

(a)
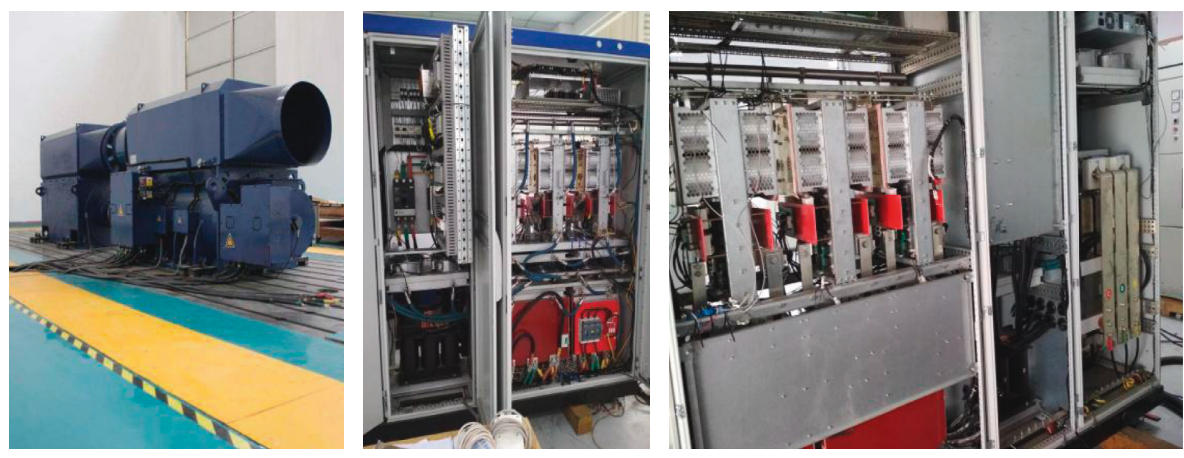

(b)

Figure 15: (a) Schematic diagram and (b) physical photograph of the experimental system.

When $k_{p}$ of the current inner loop PI controller of the gridside converter increases, the lower harmonic current of the DFIG below $1500 \mathrm{~Hz}$ is reduced, indicating that the parameter $k_{p}$ has some damping effect. Meanwhile, when $k_{i}$ of the current inner loop PI controller of the grid-side converter changes, the harmonic current of the DFIG does not change significantly, indicating that the parameter $k_{i}$ change has little effect on the harmonic output of the wind turbine, which is consistent with the theoretical analysis.

5.2.3. Altering Output Power. Figure 18 shows the current harmonic diagrams under different active power conditions, i.e., when the output active power is $300 \mathrm{~kW}$ and 
TABLE 2: Detailed parameters of the DFIG test platform.

\begin{tabular}{lc}
\hline Parameters & Values \\
\hline Rated power $\left(S_{n}\right)$ & $2 \mathrm{MW}$ \\
Rated grid frequency & $50 \mathrm{~Hz}$ \\
Rated grid voltage $\left(U_{g}\right)$ & $380 \mathrm{~V}$ \\
Rated DFIG voltage $\left(U_{d}\right)$ & $690 \mathrm{~V}$ \\
Rated DC-link voltage $\left(U_{d c}\right)$ & $1050 \mathrm{~V}$ \\
Grid-side inductance $\left(L_{g}\right)$ & $0.43 \mathrm{mH}$ \\
Grid-side capacitance $\left(C_{g}\right)$ & $120 \mu \mathrm{F}$ \\
Rotor-side inductance $\left(L_{r}\right)$ & $0.15 \mathrm{mH}$ \\
Modulation method & $S \mathrm{WPWM}$ \\
Switch frequency of the rotor-side converter & $2 \mathrm{kHz}$ \\
Switch frequency of the grid-side converter & $3 \mathrm{kHz}$ \\
\hline
\end{tabular}
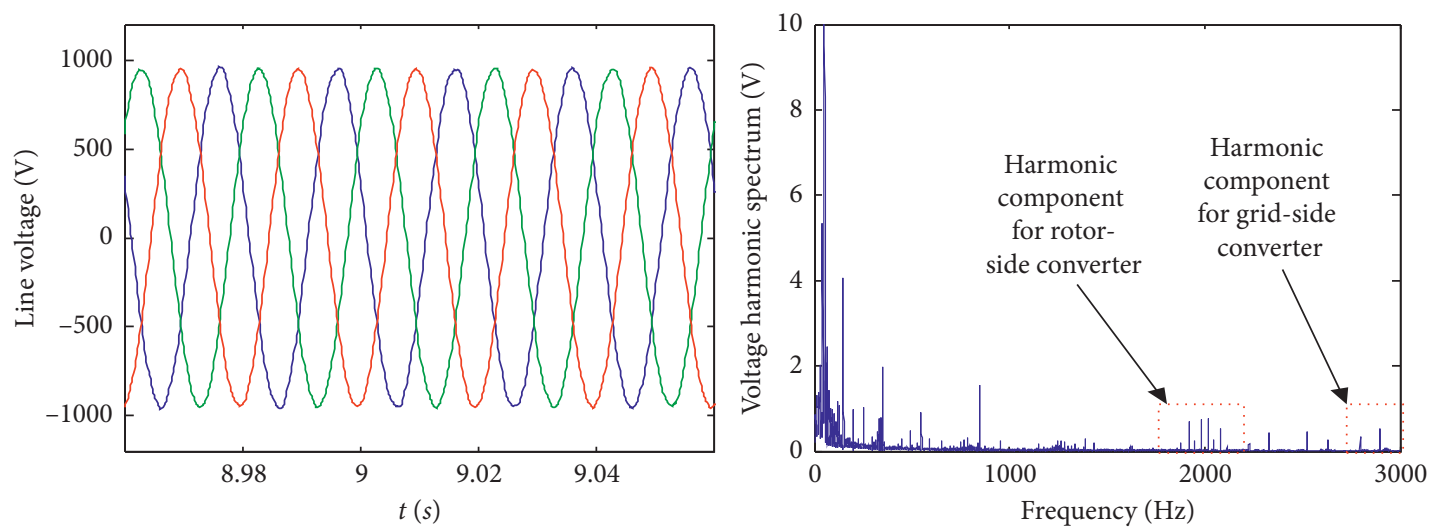

(a)
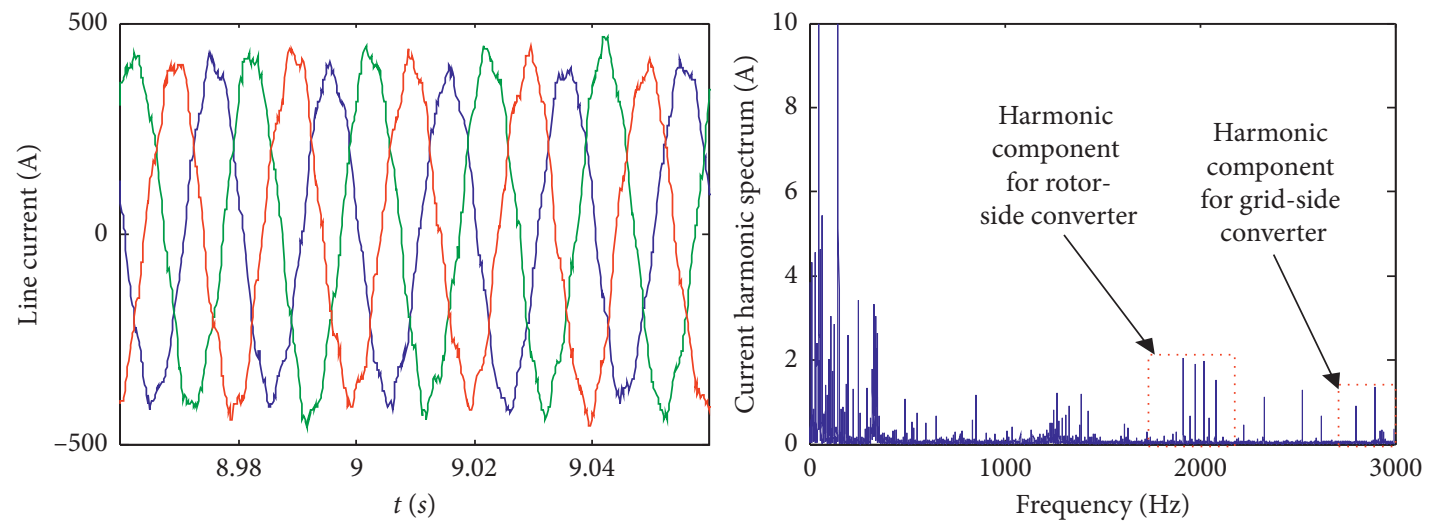

(b)

FIGURE 16: (a) Voltage waveform and harmonic spectrum and (b) current waveform and harmonic spectrum of the DFIG at PCC.

$2000 \mathrm{~kW}$, respectively. As shown in Figure 18, when the output active power of the wind turbine increases, the output power of the DFIG converter increases as well, and the harmonic current whose frequency is close to switch frequency also increases.

5.2.4. Three-Phase Voltage Unbalance. In order to verify the effect of three-phase voltage unbalance on the harmonic characteristics of the DFIG, the grid voltage irregularities were set to be $20 \%$ and $50 \%$, respectively. Figure 19 shows that the larger the unbalance of the three-phase voltage, the larger the amplitude of the $3^{\text {rd }}$ harmonic current $i_{s}$, which is consistent with the theoretical analysis.

\subsubsection{Correction of the Harmonic Model Based on Measured} Data. The harmonic model is corrected based on the harmonic test data of the test platform for the DFIG. Table 3 shows the precorrected and corrected parameters of the DFIG converter model. The simulated results shown in Figure 20 illustrate the harmonic current of the DFIG converter before and after correction under the rated operation condition. As can be seen from Figure 20, when the 

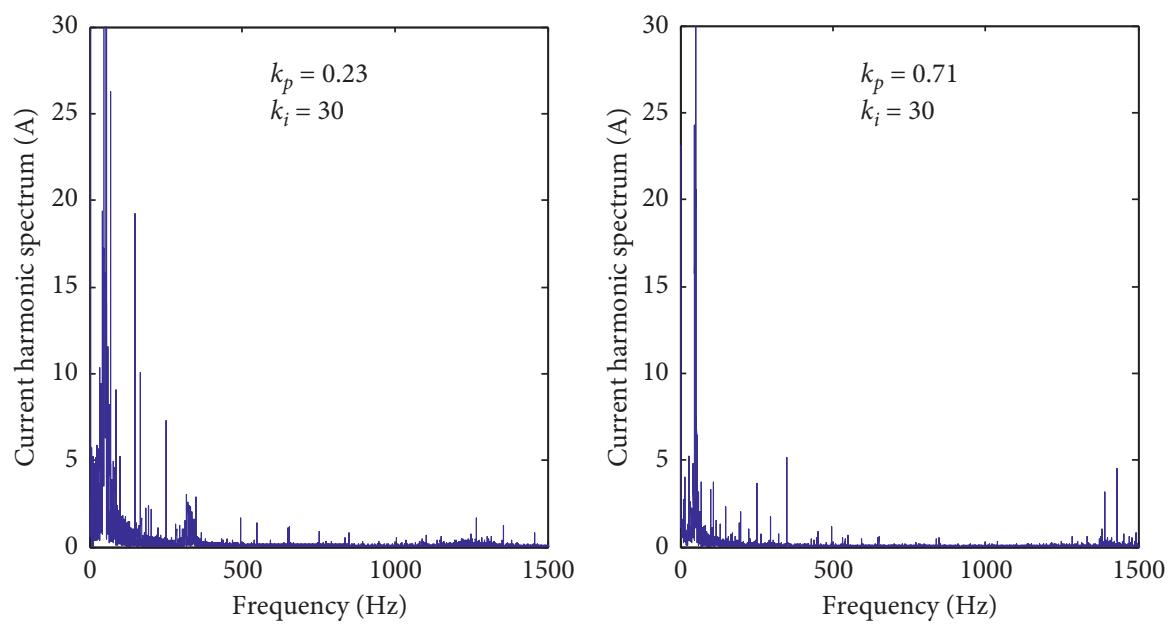

(a)
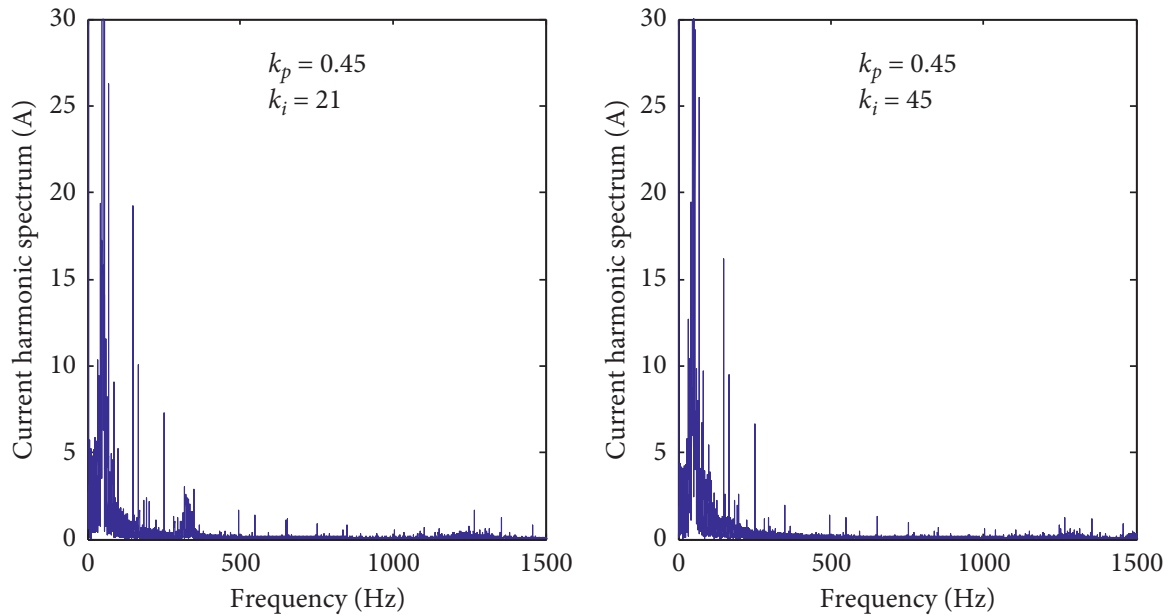

(b)

FIgURE 17: (a) Voltage waveform and harmonic spectrum and (b) current waveform and harmonic spectrum of the DFIG at PCC.
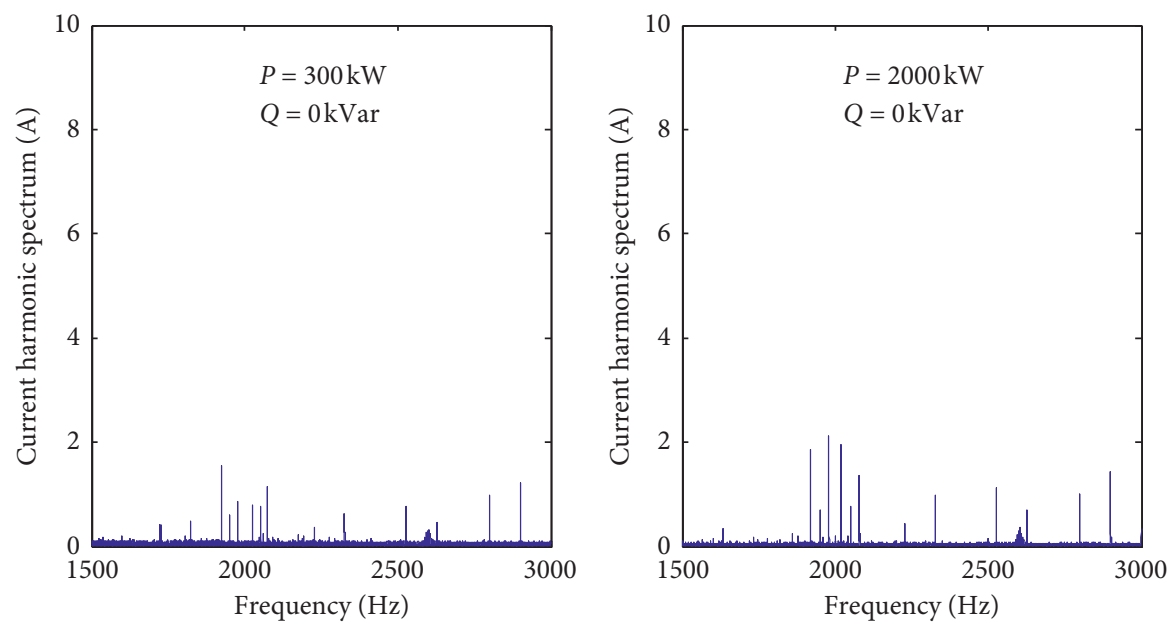

FIGURE 18: Current waveforms and harmonic spectrum of the DFIG under different active power conditions.

parameters of the simulation model are the same as those in the real test platform, the simulation results of harmonic current are much greater than what have been measured in practice. When correcting the simulation model using the data in Table 3, the value of harmonic current whose frequency is close to the switch frequency (which is 2000 and 

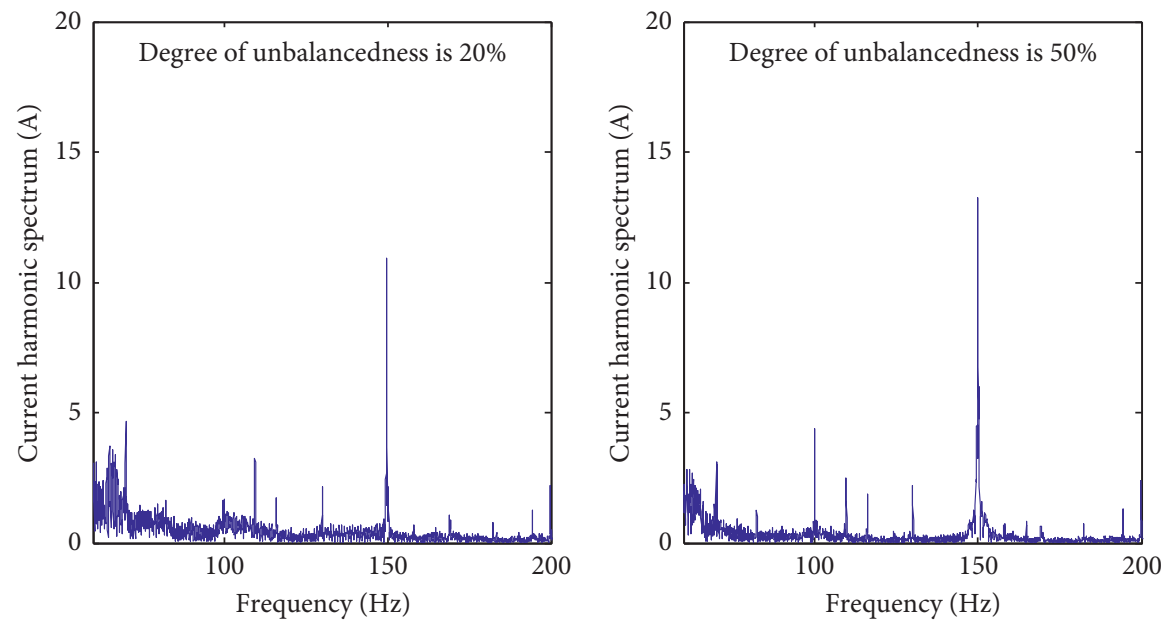

FIgURE 19: Current waveforms and harmonic spectrum of the DFIG under three-phase voltage unbalance.

TABLE 3: Model parameter correction.

\begin{tabular}{lccc}
\hline \multicolumn{1}{c}{ Parameter type } & & Precorrected parameter & Corrected parameter \\
\hline Filter parameter & $L_{1}$ & $0.43 \mathrm{mH}$ & $0.5 \mathrm{mH}$ \\
Grid equivalent inductance & $C$ & $120 \mu \mathrm{F}$ & $120 \mu \mathrm{F}$ \\
Current loop's PI control parameter of the grid-side & $L_{g}$ & - & $0.18 \mathrm{mH}$ \\
converter & $k_{p g}$ & 1 & 5.0 \\
Current loop's PI control parameter of the rotor-side & $k_{i g}$ & 13 & 100 \\
converter & $k_{p r}$ & 0.5 & 1.5 \\
\hline
\end{tabular}
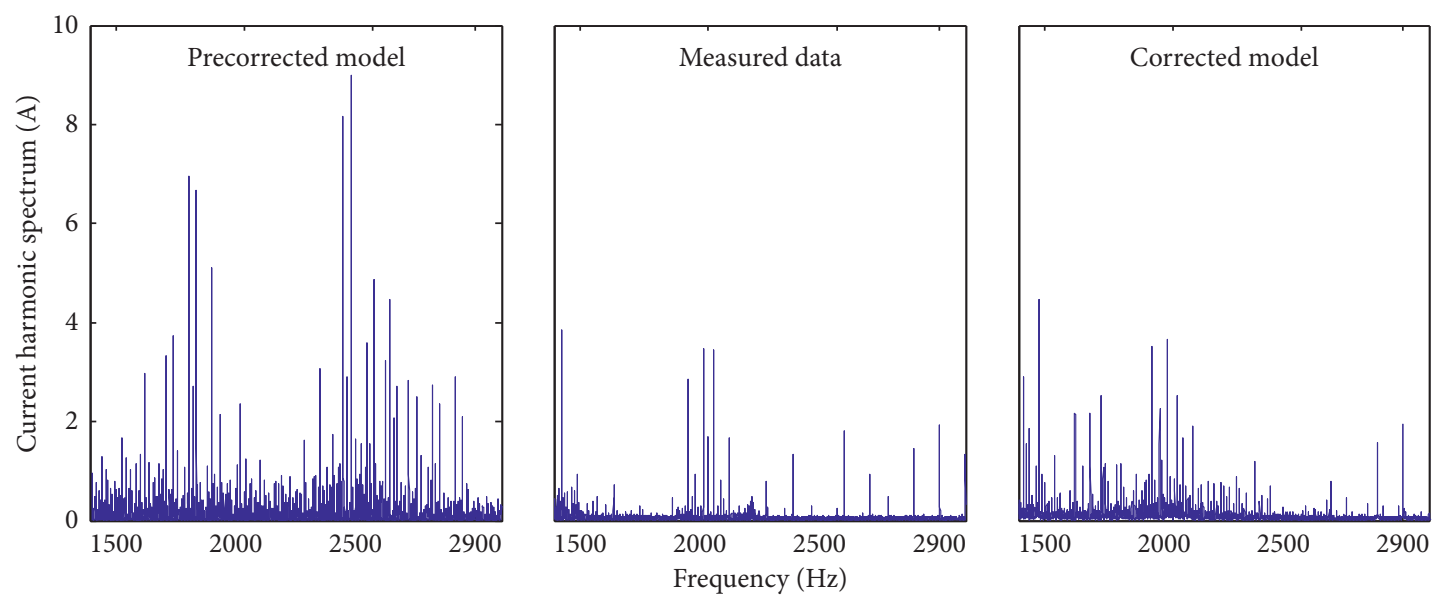

FIgURE 20: Comparison before and after harmonic model correction of the DFIG.

$3000 \mathrm{~Hz}$ ) in simulation is close to the data in the real test. Therefore, the modified model can be used to emulate the harmonic characteristics of the actual wind turbine.

\section{Conclusion}

In this paper, the harmonic equivalent models of the gridside converter and rotor-side converter of the double-fed wind power generation system are established, and the harmonic output characteristics of both converters are studied based on the established models. The researches show that the resonance of the LC or LCL filter in the grid- side converter may lead to harmonic amplification in the neighboring resonace frequency, and the harmonic amplification can be suppressed by reasonably adjusting the current controller parameter $k_{p g}$. The integral term of the current controller in the rotor-side converter resonates with the rotor leakage inductance, which may cause the lowerfrequency harmonic amplification in stator-side output current of the asynchronous motor, and the harmonic can be suppressed by appropriately increasing $k_{p r}$ and reducing $k_{i r}$ of the rotor-side current controller. The real-time HIL test results verify the correctness of the theoretical analyses. Furthermore, the effectiveness of the proposed model is 
verified based on the actual DFIG test data, which can also provide guidance for the correction of the theoretical model.

\section{Data Availability}

The data used to support the findings of this study are included within the article.

\section{Conflicts of Interest}

The authors declare that there are no conflicts of interest regarding the publication of this paper.

\section{Acknowledgments}

This research was supported by State Grid Corporation Science and Technology Project under Grant NYB17201700081 and Hubei Natural Science Foundation under Grant 2018CFB205.

\section{References}

[1] Y.-W. Shen, D.-P. Ke, Y.-Z. Sun, D. S. Kirschenau, W. Qiao, and X.-T. Deng, "Advanced auxiliary control of an energy storage device for transient voltage support of a doubly fed induction generator," IEEE Transactions on Sustainable Energy, vol. 7, no. 1, pp. 63-76, 2016.

[2] R. Tao, F. Li, W. Chen, Y. Fan, C. Liang, and Y. Li, "Research on the protection coordination of permanent magnet synchronous generator based wind farms with low voltage ride through capability," Protection and Control of Modern Power Systems, vol. 2, no. 1, pp. 311-319, 2017.

[3] Y.-W. Shen, D.-P. Ke, W. W. Qiao, Y.-Z. Sunau, D. S. Kirschenau, and C. Weiau, "Transient reconfiguration and coordinated control for power converters to enhance the LVRT of a DFIG wind turbine with an energy storage device," IEEE Transactions on Energy Conversion, vol. 30, no. 4, pp. 1679-1690, 2015.

[4] S. Liao, J. Xu, Y. Sun, Y. Bao, and B. Tang, "Control of energyintensive load for power smoothing in wind power plants," IEEE Transactions on Power Systems, vol. 33, no. 6, pp. 6142-6154, 2018.

[5] T. S. L. V. Ayyarao, "Modified vector controlled DFIG wind energy system based on barrier function adaptive sliding mode control," Protection and Control of Modern Power Systems, vol. 4, no. 1, pp. 34-41, 2019.

[6] W. Wu, Y. Liu, Y. He, H. S. H. Chung, M. Liserre, and F. Blaabjerg, "Damping methods of resonances caused by LCL-filter-based current-controlled grid-tied power inverters: an overview," IEEE Transactions on Industrial Electronics, vol. 64, no. 9, pp. 7402-7413, 2007.

[7] C. Wei, M. Benosman, and T. Kim, "Online parameter identification for state of power prediction of lithium-ion batteries in electric vehicles using extremum seeking," International Journal of Control, Automation and Systems, pp. 1-11, 2019.

[8] Y.-W. Shen, J.-R. Yuan, F.-F. Shen, J.-Z. Xu, C.-K. Li, and D. Wang, "Finite control set model predictive control for complex energy system with large-scale wind power," Complexity, vol. 2019, Article ID 4358958, 13 pages, 2019.

[9] O. Noureldeen and I. Hamdan, "A novel controllable crowbar based on fault type protection technique for DFIG wind energy conversion system using adaptive neuro-fuzzy inference system," Protection and Control of Modern Power Systems, vol. 3, no. 1, pp. 328-339, 2018.

[10] S. Boubzizi, H. Abid, A. El hajjaji, and M. Chaabane, "Comparative study of three types of controllers for DFIG in wind energy conversion system," Protection and Control of Modern Power Systems, vol. 3, no. 1, pp. 214-225, 2018.

[11] Z. Wang, Y. Z. Sun, G. J. Li et al., "Stator current harmonics analysis of double-fed induction generator," Electric Power Automation Equipment, vol. 30, no. 6, pp. 1-5, 2010.

[12] L. K. Wan, W. L. Yang, A. W. Yan et al., "Harmonic analysis of converter based on double-fed induction generator," Electric Machines \& Control Application, vol. 38, no. 8, pp. 31-35, 2011.

[13] C. J. Zhang and Q. Q. Jia, "Probabilistic harmonic load flow calculation containing double fed induction generator," Power Electronics, vol. 45, no. 11, pp. 108-111, 2011.

[14] M. Nayeripour and M. Mahdi Mansouri, "An advanced analytical calculation and modeling of the electrical and mechanical harmonics behavior of doubly fed induction generator in wind turbine," Renewable Energy, vol. 81, pp. 275-285, 2015.

[15] N. Xie, A. Luo, F. J. Ma et al., "Harmonic interaction between large-scale photovoltaic power stations and grid," Proceedings of the CSEE, vol. 34, pp. 9-16, 2013.

[16] C. Zhang, X. Wang, L. Li et al., "Study on modulation function and harmonics of SVPWM," Journal of Guizhou University (Natural Sciences), vol. 29, no. 6, pp. 63-67, 2012.

[17] J. L. Agorreta, M. Borrega, J. López, and L. Marroyo, "Modeling and control of $N$-paralleled grid-connected inverters with LCL filter coupled due to grid impedance in PV plants," IEEE Transactions on Power Electronics, vol. 26, no. 3, pp. 770-785, 2011.

[18] X. Wang, F. Blaabjerg, M. Liserre, Z. Chen, J. He, and Y. Li, "An active damper for stabilizing power-electronics-based AC systems," IEEE Transactions on Power Electronics, vol. 29, no. 7, pp. 3318-3329, 2014.

[19] D. Yang, X. Ruan, and H. Wu, "Impedance shaping of the grid-connected inverter with LCL filter to improve its adaptability to the weak grid condition," IEEE Transactions on Power Electronics, vol. 29, no. 11, pp. 5795-5805, 2014.

[20] Y.-W. Shen, L.-Q. Liang, M. J. Cui, F. Shen, B. Zhang, and T. Cui, "Advanced control of DFIG to enhance the transient voltage support capability," Journal of Energy Engineering, vol. 144, no. 2, Article ID 04018009, 2018.

[21] J. Rodriguez and P. Cortes, "Predictive control of power converters and electrical drives," IEEE Transactions on Industrial Electronics, vol. 63, no. 7, pp. 4472-4474, 2016.

[22] S. Rivera, S. Kouro, B. Wu et al., "“Multilevel direct power control-a generalized approach for grid-tied multilevel converter applications," IEEE Trans. Power Electronics, vol. 29, no. 10, pp. 5592-5604, 2014. 


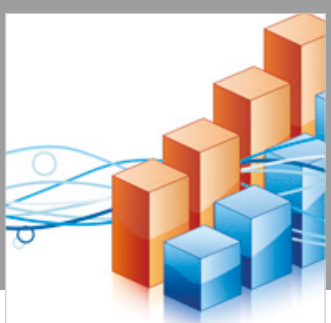

Advances in

Operations Research

\section{-n-m}
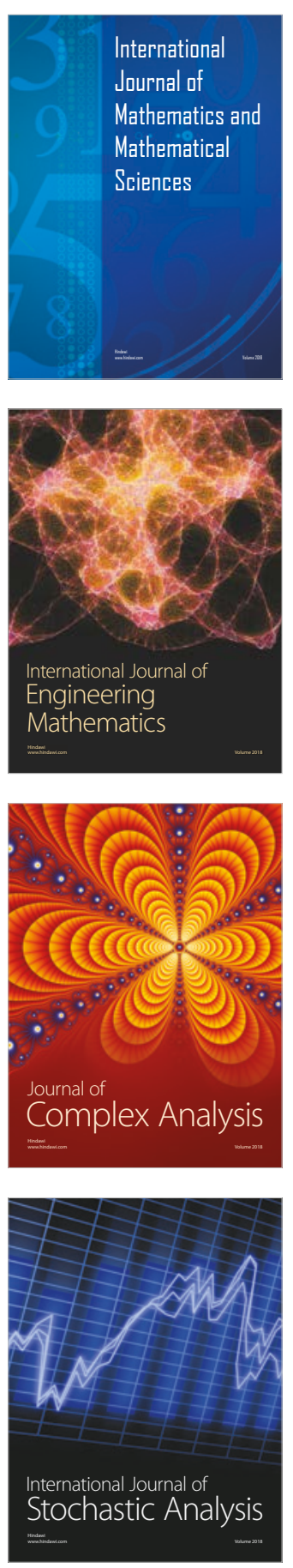
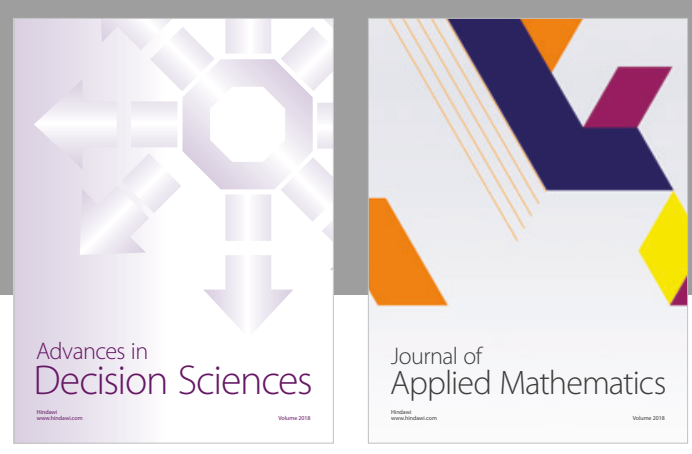

Journal of

Applied Mathematics
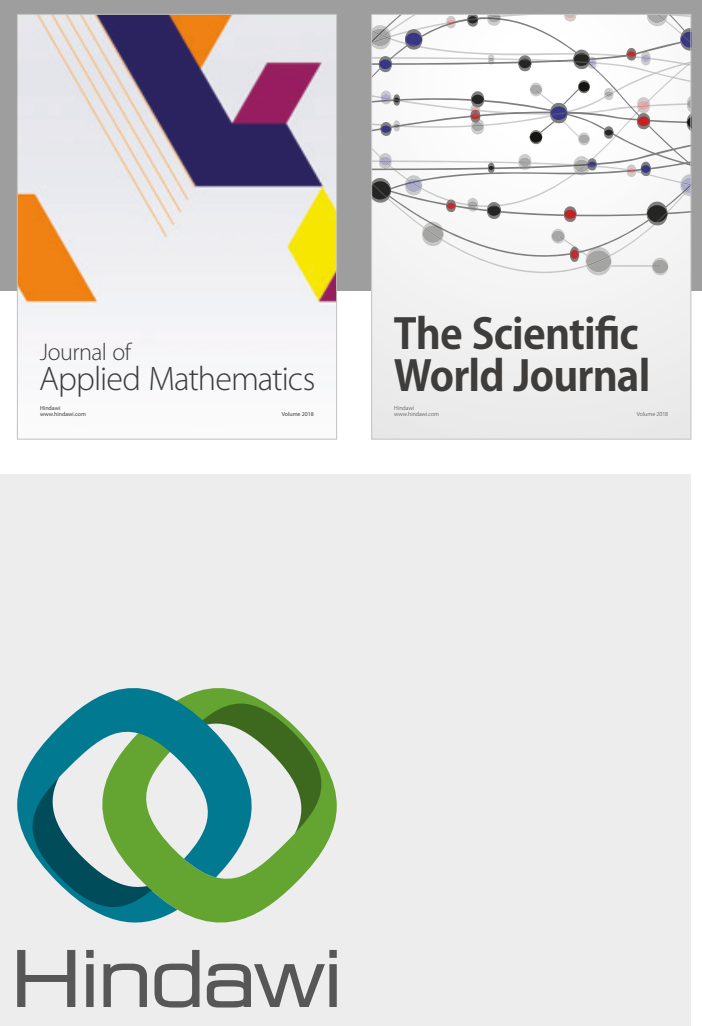

Submit your manuscripts at

www.hindawi.com

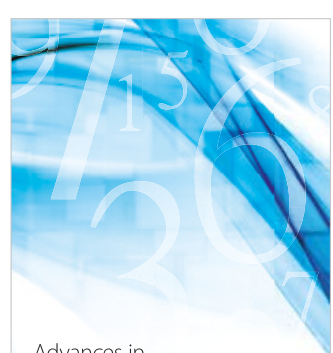

Advances in
Numerical Analysis
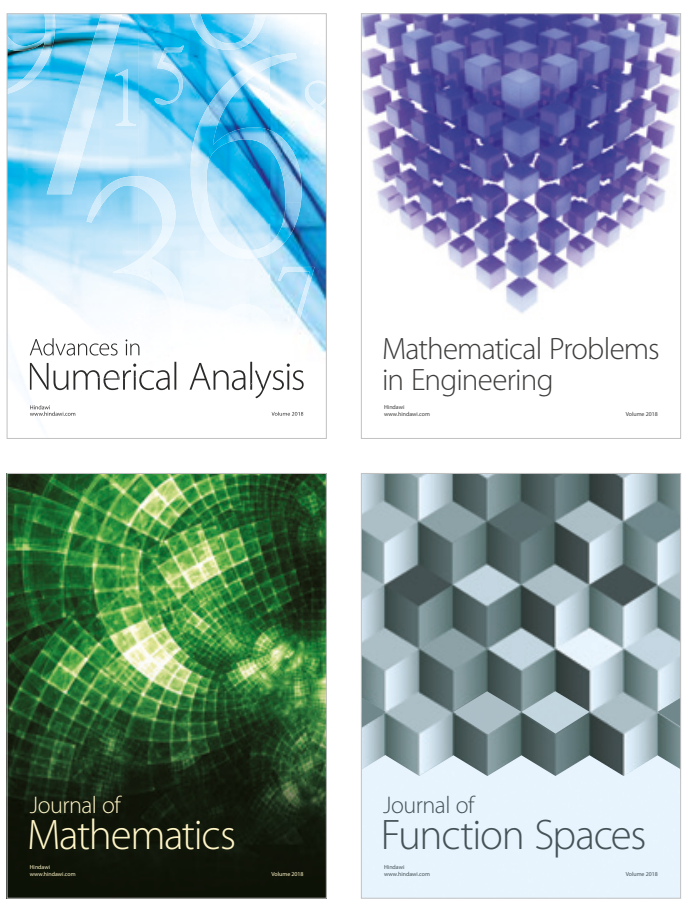

Mathematical Problems in Engineering

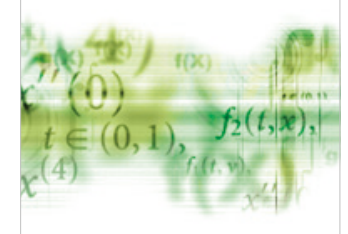

International Journal of

Differential Equations

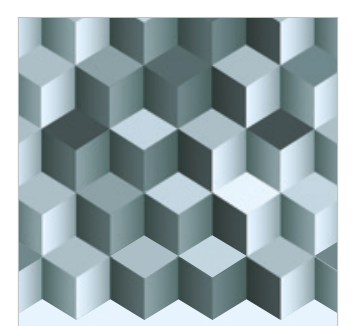

Journal of

Function Spaces
The Scientific

World Journal

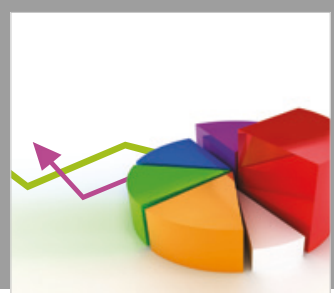

Journal of

Probability and Statistics
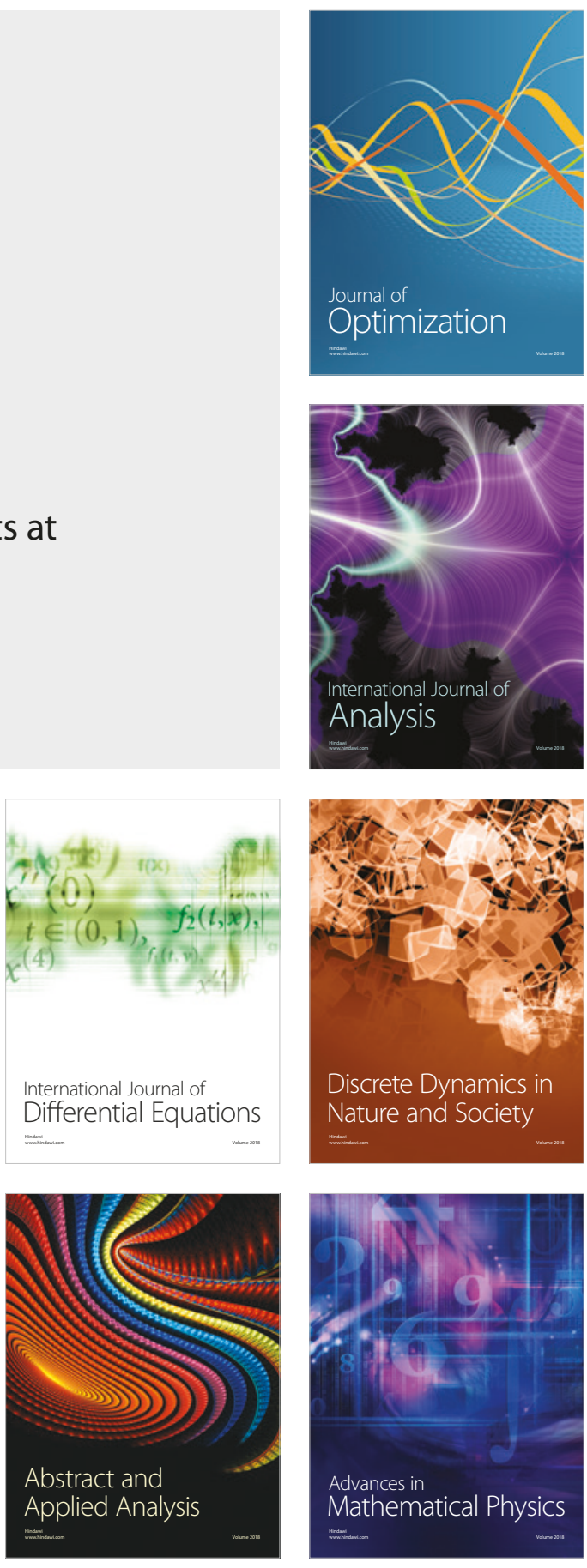